\title{
ENSINO MÉDIO: EM BUSCA DO PRINCÍPIO PEDAGÓGICO*
}

\author{
PAOLO Nosella**
}

\begin{abstract}
RESUMO: O debate sobre a problemática do ensino médio se intensificou. Não se trata de um debate novo. Porém, nestes últimos anos, ganhou novo fôlego, repercutindo inclusive nos meios de comunicação de massa. No intuito de contribuir para este debate, o texto traz informações de caráter histórico e considerações teóricas. Defende a tese de que o trabalho é o princípio educativo geral de todo o sistema escolar. A especificidade pedagógica do ensino médio decorre do momento vivido pelo jovem em busca de sua definição moral, intelectual e social. Por ser a fase final do ensino básico, é de caráter formativo não profissionalizante. A atual apologia e expansão da profissionalização precoce é uma declaração da falência e do abandono do ensino médio público, humanista, "culturalmente desinteressado", destinado a preparar dirigentes.
\end{abstract}

Palavras-chave: Educação. Ensino médio. Trabalho e educação. Princípio pedagógico.

\section{HigH SCHOOL: IN SEARCH OF A PEDAGOGICAL PRINCIPLE}

ABSTRACT: The debate on the problems of high school has intensified. Although it is not new, it has recently been given a new impetus, and has even been relayed by the mass media. To contribute to this debate, this text provides historical information and theoretical considerations. It defends the thesis that work is the general education principle of the entire school system. High school has to be specific because it is intended for youth in search of their moral, intellectual and social definition. Because it is the final stage of basic education, it must not be based on students' professionalization. The current defense and the expansion of early professional education are a petition for bankruptcy and abandonment of humanist, "culturally disinterested" high school designed to prepare leaders.

Key words: Education. High school. Work and education. Basic pedagogical.

\footnotetext{
* Texto apresentado no vi Colóquio de Pesquisa sobre Instituições Escolares, promovido pelo Programa de Pós-Graduação em Educação da Universidade Nove de Julho (UNINOve-SP), em 27/08/2009, e no encerramento do v Simpósio sobre Trabalho e Educação, promovido pelo Núcleo de Estudos sobre Trabalho e Educação, da Faculdade de Educação da Universidade Federal de Minas Gerais (UfMG), em 28/08/2009. O mesmo texto foi apresentado no Seminário Nacional de Políticas para o Ensino Médio, a convite do Ministério da Educação (Brasília, 23 de set. 2009).

* Doutor em Filosofia da Educação e professor do Programa de Pós-Graduação em Educação da Universidade Nove de Julho (UNINOvE). E-mail: nosellap@terra.com.br
} 


\section{LYCÉE: À LA RECHERCHE DU PRINCIPE PÉDAGOGIQUE}

RÉSUMÉ: Le débat sur la problématique du lycée s'est intensifiée. Même s'il n'a rien de nouveau, il a connu un regain ces dernières années, et a même été répercuté par les médias. Pour contribuer à ce débat, ce texte apporte des informations à caractère historique et des considérations théoriques. Il soutient la thèse de ce que le travail est le principe éducatif général de tout le système scolaire. La spécificité pédagogique du lycée se doit au fait que ses élèves sont des jeunes en quête de leur définition morale, intellectuelle et sociale. Comme il s'agit de la phase finale de l'enseignement de base, il vise à la formation et non pas à la professionnalisation. L'apologie actuelle et l'expansion de la professionnalisation précoce sont une déclaration de faillite et d'abandon du lycée public, humaniste, "culturellement désintéressé", destiné à préparer des dirigeants.

Mots-clés: Éducation. Lycée. Travail et éducation. Principe pédagogique.

\section{Premissa}

$\mathrm{R}$ ecentemente, o debate sobre o ensino médio se intensificou. Não se trata de um debate novo. Porém, nestes últimos anos, ganhou novo fôlego. O tema repercute inclusive nos meios de comunicação de massa. Há uma convicção generalizada de que, se todo o ensino no Brasil é bastante deficitário, o ensino médio o é mais ainda. Uns defendem uma formação humanista e científica única e para todos; outros, uma formação pré-profissional ou até mesmo profissionalizante; outros ainda defendem a separação entre o ensino médio regular e o ensino técnico e profissional; e outros, finalmente, defendem o ensino médio integrado ao ensino técnico ou à educação profissional.

Também do ponto de vista administrativo há divergências. Para muitos, a formação dos jovens é tarefa exclusiva do Ministério da Educação e das Secretarias de Educação dos estados; para outros, a preparação técnica e profissional é de competência das Secretarias de Desenvolvimento e Tecnologia ou de outras instituições públicas congêneres. Mas há quem defende que a formação técnica e profissional é tarefa das instituições privadas voltadas às atividades práticas, pois estas sabem como formar seus quadros produtivos e tendem naturalmente a criar suas escolas próprias.

Quanto ao currículo e à duração do ensino médio, as opiniões, as iniciativas e a legislação também são muitas e variam: para o ensino médio regular, muitos defendem que três anos de estudo são suficientes. Porém, para o ensino médio integrado, acrescentam um ano; outros acham que o jovem brasileiro entra na universidade cedo demais e que, portanto, todo o ensino médio deveria se desenvolver em quatro anos. Quanto aos cursos técnicos ou profissionalizantes, separados do ensino médio regular, as opiniões sobre sua duração variam, desde poucas semanas até um ano e meio ou, no máximo, dois. 
Obviamente, o debate sobre o ensino médio se aguçou, sobretudo, pelo grande crescimento das suas matrículas em decorrência do aumento dos concluintes do ensino fundamental. Os dados levantados pela Pesquisa Nacional por Amostra de Domicílios de 2008 (PNAD-IBGE) mostram que o atendimento aos jovens de 15 a 17 anos, pela primeira vez, superou a barreira de $84 \%$ (Folha de S. Paulo, 19 set. 2009). Infelizmente, diante desse crescimento, muitos se preocupam tão somente em "acomodar" socialmente tamanha demanda de jovens em busca de formação. Esperam, inclusive, tirar proveito material dessa mão de obra juvenil e, por isso, pensam em profissionalizá-la rápida e precocemente. Assim, fazem diariamente a apologia do ensino técnico profissionalizante "que contemple principalmente os alunos do ensino médio":

Mão-de-obra-difícil. A recente aprovação, no Senado, da Rede Federal de Educação Profissional, Científica e Tecnológica é um passo pequeno, ainda que na direção correta, para preencher uma das grandes lacunas na formação dos brasileiros: o ensino profissional. (...). Para ser bem sucedida, é importante que essa expansão contemple principalmente os alunos do ensino médio. (Folha de S. Paulo, Editorial, 28 dez. 2008)

Não nos enganemos, não é amor à Escola do Trabalho. É um movimento político de acomodação social e de exploração de mão de obra jovem. Aliás, a ideia de oferecer cursos rápidos, práticos, que atendam ao mercado e "acomode" muitos jovens, se apresenta como democrática. Consequentemente, dizem, isso irá fortalecer também o tradicional ensino médio "abstrato", "demorado", embasado numa cultura geral "abstrata" ou "inútil".

A problemática referente ao estatuto pedagógico do ensino médio regular não preocupa apenas educadores e políticos do Brasil, mas também de muitos outros países econômica e socialmente avançados. Com efeito, o ideário da escola unitária dos anos de 1920/1930, que inspirou reformas que eliminaram a dualidade escolar do antigo ginásio (entre 10 e 13 anos), ainda não conseguiu alavancar uma nova estrutura normativa, unitária e universal, para o ensino médio regular (entre 14 e 18 anos).

No intuito de contribuir para esse debate, o presente texto traz informações de caráter histórico e considerações teóricas. Defendo a tese de que o trabalho produtivo, em sua concepção ampla, "mercadologicamente desinteressado", é o princípio educativo geral de todo o sistema escolar. O princípio pedagógico específico do ensino médio, fase final da educação básica, decorre do momento vivido pelo jovem em busca de sua autonomia e identidade moral, intelectual e social. É marcado, portanto, pela transição da fase da aprendizagem prioritariamente heterônoma para a fase da aprendizagem autônoma. A atual apologia e ampliação do ensino médio profissionalizante é uma declaração implícita da falência e do abandono do ensino médio regular, ao mesmo tempo em que expressam o agravamento da dualidade social e escolar. 


\section{O ensino médio no Brasil}

Dizíamos que o debate sobre ensino médio não é novo. Sua dualidade, escola secundária para dirigentes e profissional para preparar os quadros do trabalho, é antiga e ainda hoje perdura, apesar dos muitos "esforços" para superá-la ou para dissimulá-la. Ironicamente, o ensino médio só não foi dual quando, antes do processo de industrialização, simplesmente excluía da escola os jovens destinados ao trabalho.

A partir dos anos 30 do século passado, com o advento da industrialização, foi organizado no país um sistema de ensino profissional, estabelecendo legalmente a dualidade pedagógica, correspondente à dualidade social:

Como desdobramento da Constituição de 1937, a Lei Orgânica do Ensino Secundário, de 1942, estabeleceu a dualidade do sistema, explicitando que a escolarização, depois do primário obrigatório de quatro anos, teria duas vertentes: o ensino secundário regular - em dois ciclos perfazendo sete anos - destinado às "elites condutoras" e o ensino profissionalizante - também em dois ciclos em sete anos - para as classes populares. (Dagmar, 2005, p. 4)

Isso não ocorreu somente no Brasil. Com variáveis, aconteceu no mundo industrializado em geral.

A instituição formal da dualidade do sistema escolar, por contraste, mobilizou muitos educadores idealistas que, por defenderem a igualdade social, levantaram a bandeira da escola única. Por exemplo, a proposta de escola única de Anísio Teixeira propunha uma escola igual para todas as crianças e jovens a despeito de suas diferenças sociais.

Inúmeras foram as tentativas de harmonizar a escola humanista com a escola do trabalho, quer no âmbito da equivalência dos diplomas, quer no âmbito da integração dos currículos. A Lei de Diretrizes e Bases de 1961 (Lei n. 4.024/61) foi um marco, pois possibilitou aos diplomados das escolas técnicas o ingresso no ensino superior. A forma política como isso aconteceu merece ser registrada. Jorge Amado era deputado pelo Partido Comunista na Câmara Federal e integrava a Comissão de Educação e Cultura. Paschoal Lemme, que o assessorava nas questões escolares, nos diz:

Eu resolvi fazer um projetozinho para ele apresentar na Câmara. Esse projeto, com apenas dois artigos, dizia o seguinte: todos os estudantes que completarem os sete anos de ensino de grau médio, não importa o tipo, teriam o direito a concorrer ao vestibular para as universidades. Entreguei a ele e, com aquela confusão, não pude explicar exatamente o alcance daquilo. Ele começou a receber telegramas elogiosos de todo o Brasil. Ficou pasmo. Expliquei a ele que só quem fazia o curso secundário é que tinha o privilégio de fazer o vestibular para o ensino superior. Os outros faziam sete anos, às vezes são rapazes mais amadurecidos até do que esses meninos de famílias mais ricas 
e, no entanto, estão proibidos. Só o ensino comercial, de nível bastante mais elevado, mais tarde permitia chegar ao curso de administração. Era isso que estava acontecendo. Eu generalizava o privilegio para todos os que fizeram sete anos de grau médio; todos tinham o direito de provar sua capacidade no vestibular, em igualdade de condições. De certa forma quebrava um pouco aquela organização de Capanema que reconhecia as classes existentes. Sem mascará-las num tipo de ensino unitário, como o profissionalizante compulsório. (Lemme, 1988, p. 324-325)

As últimas palavras da citação se referem especificamente à reforma educacional dos governos militares, Lei n. 5692/71, aparentemente o ponto mais alto da evolução da ideia de escola média única, para todos. É curioso constatar que a aversão ao idealismo pedagógico levou comunistas convictos, como o professor Paschoal Lemme, por exemplo, a preferir o "realismo" das leis orgânicas do ensino de Capanema, que formalmente transfere a divisão da sociedade em classes na estrutura do ensino, à hipocrisia da Lei n. 5.692/71, que propõe a escola única do trabalho numa sociedade que produz cidadãos cada vez mais diferentes. Nas palavras do próprio Lemme:

\begin{abstract}
O Estado Novo foi um regime muito contraditório (...). Houve a criação do senaI e do SENAC que foram consideradas iniciativas interessantes para a formação de mãos de obra. Capanema tinha certa rivalidade com aquilo, ele preferia fazer as escolas técnicas, uma em cada estado, que ele acabou fazendo. Por incrível que pareça, acho a organização do ensino secundário que ele fez muito mais realista do que esta lei da ditadura (5.692/71), essa lei de colocar o profissionalizante metido numa escola, uma coisa inteiramente irreal. Ele fez logo as coisas às claras, fez o ensino secundário, o único que conduzia à universidade, e fez, em segundo lugar, um ensino industrial, um ensino comercial, um ensino agrícola para as classes de nível econômico um pouco menor... e o ensino normal. Assumiu as classes sociais: não sei se é elogiável, mas é interessante. (1988, não publicada)
\end{abstract}

A Lei n. 5.692/71 estabelecia três anos de ensino médio (ensino de $2^{\circ}$ grau) para os jovens de 15 a 17 anos, com profissionalização obrigatória. Houve interferências importantes do setor empresarial no Congresso da época para a determinação da compulsoriedade profissional da referida Lei. Tanto o ministro da Educação, Jarbas Passarinho, como o professor Valnir Chagas recusam a qualificação da lei da profissionalização compulsória como autoritária e ingênua. Chagas, em seu depoimento, assim sintetiza a trajetória da integração do ensino profissional com o secundário:

A Lei de Diretrizes e Bases de 1961 gerou muita frustração... No dia seguinte ao da promulgação dessa Lei, começamos a luta. Anteriormente a essa Lei tinha havido a equivalência do ensino profissional com o secundário, em nível de ginásio. Em 1953 houve a equivalência em nível colegial. No entanto, em ambos os casos, o aluno estava sujeito à adaptação às matérias do secundário que ele não tivesse feito, porque a estrada real para a universidade era, como dizia Capanema, a escola secundária. A Lei de Diretrizes e Bases deu esse terceiro passo, ou seja, sem adaptação. Porém, no dia seguinte à 
(promulgação) da Lei de Diretrizes e Bases, começou-se a dizer: "quem diz equivalente, não diz igual". Há o dualismo, há uma classe rica... e outra, apenas equivalente, mas não igual. Aí começou a luta: batalhar pela escola única (...). Nós não propusemos a escola única, sabendo que não poderíamos caminhar para a escola única de vez. Exatamente considerando que a sociedade é de classes. (Chagas, op. cit.)

O fracasso da profissionalização compulsória da Lei n. 5.692/71 dos governos militares era previsível: na verdade, sob a retórica de liquidar a escola secundária, verbalista e elitista, escondia-se o projeto de extinguir uma escola formadora de dirigentes (ou de controladores dos dirigentes), fundamental princípio unitário do ensino secundário. $\mathrm{O}$ sonho educacional dos militares era universalizar uma escola de técnicos submissos, de operadores práticos. Ou seja, criava-se a "unitariedade" do sistema escolar, cortando a parte crítica e humanista do currículo.

Imediatamente, evidenciou-se o artificialismo das inúmeras e compulsórias habilitações profissionais. A escola humanista foi empobrecida e o ensino técnico esvaziado. O equívoco foi reconhecido e corrigido pelo governo, pois a própria sociedade civil o havia percebido. Em 1982, foi promulgada a Lei n. 7.044, determinando que a profissionalização não mais fosse obrigatória, mas sim opcional de cada escola, isto é, de cada grupo ou classe social.

Restabelecido o realismo escolar, o debate sobre o ensino médio unitário arrefeceu. Todavia, independentemente dos debates e das políticas governamentais, as camadas populares, durante a década de 1980, pressionaram por mais escolarização, inclusive média. Para dar atendimento a essa demanda, o Estado simplesmente ampliou esse ensino, dando continuidade à política educacional populista que facilitava a diplomação sem maiores preocupações com a qualidade. Esse período caracterizou-se pela expansão dos cursos noturnos e supletivos. Democratizava-se a clientela, mas deformava-se o método.

A Constituição de 1988 foi a oportunidade de reacender o debate sobre a educação, a organização do sistema de ensino e sua qualidade. Com vistas à elaboração da nova Lei de Diretrizes e Bases (LDB), o debate sobre ensino médio se polarizou: de um lado (neoliberal), procura-se requalificar a tradicional escola propedêutica, reforçar a meritocracia e reencontrar a identidade própria do ensino técnico, retirando de seu currículo as disciplinas de conteúdo geral. De outro lado (popular), levantou-se a bandeira da politécnica, densa de significação, embora politicamente inadequada, pela sua ambiguidade semântica e conceitual.

A nova LDB de 1996 buscou superar a contraposição entre a visão neoliberal e a popular, introduzindo a ideia de uma escola média cujo objetivo fosse integrar, no amplo conceito de cidadania, a participação do jovem à vida política e produtiva. Naturalmente, quando os conceitos são bastante amplos e ambíguos, abrigam todas as posições e cada grupo social fica com a sua prática. 
Em 1997, o grupo político hegemônico (governo FHC), por decreto federal, "determinou que o ensino técnico, organizado em módulos, seja oferecido separadamente do ensino médio regular" (Dagmar, 2005, p. 8). Estranho decreto: afastando legalmente o ensino técnico e profissional do ensino médio, liberava o ensino profissional de qualquer limitação ou controle burocrático, abandonando o ensino médio regular público no baixo nível a que chegara.

Esse Decreto constituiu-se no alvo principal das críticas dos que defendem a integração entre formação geral e técnica. Ao Governo Lula coube atender a essa crítica e tentar soluções. Mas, como este governo não foi de rupturas, suas políticas não promoveram efetivas inovações no ensino médio. O Decreto n. 5.154/2004 permite tudo: tanto o ensino médio separado, como o integrado. O debate está em curso e centra-se, sobretudo, no âmbito da problemática curricular e na busca de experiências interessantes. As palavras recorrentes são: integração, articulação, interdisciplinaridade e inovação. Os eixos orientadores do ensino médio devem ser: trabalho, ciência, tecnologia e cultura.

A primeira iniciativa importante que o governo do pr tomou foi, obviamente, a revogação do Decreto n. 2.208/97. No âmbito das políticas para o ensino médio, essa determinação era entendida como o compromisso político mais importante do novo governo com os educadores progressistas. À separação obrigatória entre o ensino médio regular e o ensino técnico profissionalizante do governo anterior haveria de se contrapor, de forma opcional, um projeto de ensino médio integrado à educação profissional. Essa integração, em princípio, é irrepreensível, mas, na prática, levanta sérias preocupações de caráter conceitual, de currículo e de gestão. Integração de cultura geral e profissional não é justaposição de conteúdos, nem subsequência, nem concomitância. É articulação. Mas qual o elemento articulador? O termo/conceito "integrado" é sedutor e instigante, mas é polissêmico, podendo chegar a ser ambíguo e enganoso.

\section{Em busca do princípio pedagógico do ensino médio}

O trabalho como princípio educativo foi pensado e proposto a partir do processo de industrialização, no qual os homens compreenderam que o conhecimento científico necessário à indústria era fruto da articulação entre as atividades práticas e os estudos teóricos, uma vez que a inteligência e as mãos executavam, conjuntamente, operações segundo regras objetivas teóricas e práticas. Pela experiência científica, criava-se uma nova forma histórica de interação entre homem e natureza, um novo método de produção. Assim, o trabalho como princípio educativo passou a significar o objetivo geral de todo processo educativo, isto é, capacitar às gerações mais novas a transformar a natureza, de forma científica, humanizando-a. Destarte, à instituição 
escolar competia desenvolver atividades didáticas próprias de cada fase etária (o trabalho como princípio pedagógico), visando a alcançar o objetivo geral.

O marxismo foi a escola teórica que mais levou adiante o ideário iluminista da integração entre artes mecânicas e liberais. Sua proposta pedagógica visava a superar o estigma da dicotomia entre os que fazem e os que dirigem, entre operários e cientistas, entre intelectuais e trabalhadores, afirmando que o processo educativo geral e escolar do homem está embasado no trabalho produtivo industrial, com vistas a formar dirigentes trabalhadores.

O próprio Marx testou progressivamente as formas didáticas da articulação entre trabalho produtivo e escolar. Assim, em 1848, nos Princípios básicos do comunismo e no Manifesto, recomenda "combinar educação e trabalho fabril", referindo-se inclusive à educação infantil. Quase 20 anos depois, nas Instruções aos delegados e em O capital (1866-1867), apresenta pela primeira vez a ideia da educação politécnica e tecnológica, como formas pedagógicas de integração do trabalho produtivo e escolar. Ainda mais tarde, em 1875, no Programa de Gotha, a escola é vista por Marx na ótica política da luta de classes, afirmando que não pode haver na sociedade burguesa escolas didaticamente iguais para classes desiguais (Manacorda, 2007a, p. 35-42).

Após a Revolução Socialista de 1917, a União Soviética implementou as primeiras leis escolares, reafirmando o princípio marxiano da unidade entre instrução e trabalho produtivo com base na formação politécnica. Sobre essa temática, ocorreu na época um memorável debate: de um lado, havia os defensores da "morte da escola" (Sulghin e Krupenina) (Mauro, 1980, p. 193) e, de outro, os defensores da profissionalização precoce chamada também de monotécnica. Contra estas duas posições, se pronunciaram Lênin, Krupskaja e Blonsky, defendendo a "politecnicização" do sistema escolar. O que importa ressaltar é que nesse debate foram levantadas duas preocupações importantes: a) existem no sistema escolar diferentes formas pedagógicas de aplicação da politécnica; b) é definida a noção de trabalho produtivo "mercadologicamente desinteressado", isto é, formativo, inserido na escola.

Quanto à primeira preocupação, o grupo político ao qual Lênin e Krupskaja pertenciam (Narkompros) defendeu a identificação conceitual e prática entre o jogo e o trabalho para a escola infantil, enquanto, para os alunos do ginásio e do ensino médio, o trabalho de fábrica ou de oficina devia estar "rica e verdadeiramente articulado com a atividade de estudo" (idem, ibid.). Krupskaja, sem negar o valor da convivência das crianças e dos jovens com os adultos nas fábricas, "afirmava ser impossível introduzir nas fábricas crianças e adolescentes, pois dizia se tratar de um trabalho superior às suas forças" (ibid.). Ao comentar os laboratórios escolares relacionados com a produção, "insistia que neles não houvesse exclusivamente exercitação" (ibid.). 
Quanto à segunda preocupação, esses primeiros pedagogistas soviéticos defenderam a noção de trabalho produtivo "desinteressado", isto é, formativo: "o trabalho, enquanto novo elemento a ser introduzido na escola, era sempre representado como criativo e não repetitivo, fonte de sempre novos conhecimentos e capaz de desenvolver o hábito da organização, da direção e das atividades coletivas" (Mauro, op. cit., p. 193).

É inegável o fascínio que a expressão "trabalho produtivo" e sua íntima conexão com o processo educativo escolar suscitavam nos educadores socialistas do início do século xx. Entretanto, a prática educativa cada vez mais evidenciava que o trabalho produtivo não era de per si educativo se não fosse mercadologicamente "desinteressado" e acompanhado por uma explícita instrução e educação política. Makarenko (apud Mauro, 1980, p. 194) escrevia: “Nós estávamos excessivamente acostumados a adorar o principio do trabalho". Mais adiante, observa que existe contradição entre a afirmação abstrata sobre instrução politécnica e a iniciação concreta dos jovens no mundo do trabalho (idem, ibid.).

Paralelamente, no Instituto de Psicologia da Universidade de Moscou, pesquisadores importantes como Vygotsky, Leontiev, Luria e Elkonin, ao explicarem como o trabalho produtivo é o principio pedagógico, mudam o eixo de análise do instrumento técnico focando o sujeito humano. Nesse contexto, insere-se a contribuição de Antonio Gramsci. Para ele, a pessoa humana se integra nos processos do trabalho produtivo e de luta pela hegemonia política, descobrindo e desenvolvendo sua tendência profunda e seu talento, com coerência e disciplina, tornando-se uma personalidade consciente. Descoberta e desenvolvimento que se dão lentamente, ao longo da carreira escolar, integrando o "reino da necessidade com o reino da liberdade" (Gramsci, 1975b, p. 1487), isto é, integrando um núcleo de disciplinas do currículo obrigatório com atividades e opções de próprio interesse. A passagem da individualidade caótica para a personalidade coerente não pode ocorrer forçadamente, por precoce necessidade de sobrevivência material, mas pela educação disciplinada e orientada, no tempo adequado.

Assim, o trabalho produtivo "desinteressado", como princípio educativo geral, embasa todo o sistema escolar, a educação infantil, o ensino fundamental, o ensino médio. (Com efeito, aprender as quatro operações da matemática no ensino fundamental não é menos importante, com relação ao trabalho produtivo, do que aprender as operações exponenciais no ensino médio) Daí a pergunta: existe um princípio pedagógico específico do ensino médio? Como nós, Gramsci se põe esta questão: "O problema fundamental se coloca com respeito à fase da carreira escolar representada pelo ensino médio, que em nada se diferencia, atualmente, como tipo de ensino, das fases escolares anteriores (...)" (1975b, p. 1536). 
Para responder a essa pergunta, o pensador italiano recorre à psicologia e, no intuito de identificar o princípio pedagógico específico do ensino médio, atribui grande importância à puberdade e à adolescência. Todos passam pela puberdade, embora nem a todos seja dado o direito de vivenciar a adolescência, durante a qual o jovem, por meio de experiências orientadas, se define moral, intelectual e socialmente. A conclusão de Gramsci é que o jovem adolescente se caracteriza pelo processo de busca de maior autonomia, livrando-se da dependência mecânica e absoluta dos adultos. É a fase mais delicada de desenvolvimento da responsabilidade individual e da criatividade:

Do ensino quase puramente dogmático (infantil e fundamental), quando a memória desempenha grande papel, passasse à fase criativa ou de trabalho autônomo e independente; da escola com disciplina do estudo imposta e controlada autoritariamente passasse à fase do estudo ou de trabalho profissional onde a autodisciplina intelectual e a autonomia moral são teoricamente sem limites. E isto ocorre logo em seguida à crise da puberdade, quando o ímpeto das paixões instintivas e elementares continua a lutar contra os freios do caráter e da consciência moral em formação. (Idem, ibid.)

\section{Enfim, o princípio pedagógico específico do ensino médio não deve ser busca-} do na preparação para o mercado, mas no método de estudo e pesquisa:

Frequentemente se comete na educação das crianças este erro: não se distingue que na vida das crianças existem duas fases muito distintas, antes e depois da puberdade. Antes da puberdade, a personalidade do menino ainda não se formou e é mais fácil guiar a sua vida e fazê-lo adquirir determinados hábitos de ordem, de disciplina, de trabalho; depois da puberdade, a personalidade se forma de modo impetuoso e toda intervenção exterior torna-se odiosa, tirânica, insuportável. Ora, ocorre justamente que os pais sentem a responsabilidade pelos filhos logo neste segundo período, quando é tarde: entram então naturalmente em cena a palmatória e a violência, que além do mais dão muito poucos frutos. Por que, ao contrário, não se ocupar da criança no primeiro período? Parece pouco, mas o hábito de estar sentado diante da carteira 5, 8 horas por dia é uma coisa importante, que se pode fazer com bons modos até os 14 anos, mas em seguida não se pode mais. (Gramsci, 1975a, p. 364)

\section{Concluindo, no Caderno 12, Gramsci assim sintetiza o princípio pedagógico} do ensino médio:

A última fase da escola unitária (ensino médio) deve ser concebida e organizada como fase decisiva, na qual se tende a criar os valores fundamentais do "humanismo", a autodisciplina intelectual e a autonomia moral necessárias a uma posterior especialização, seja ela de caráter científico (estudos universitários), seja de caráter imediatamente práticoprodutivo (indústria, burocracia, comércio etc.). O estudo e o aprendizado dos métodos criativos na ciência e na vida devem começar nesta última fase da escola. (2000, p. 39)

Em outras palavras, a puberdade é uma revolução orgânica natural e universal que fundamenta o direito à adolescência, isto é, a um período de 6 a 7 anos de 
busca para os jovens identificarem e ensaiarem seus potenciais intelectuais, artísticos, científicos. Mas, quando aos jovens foi negada a aprendizagem dos hábitos e habilidades intelectuais próprias do ensino fundamental, no ensino médio torna-se extremamente difícil a recuperação e o caminho para a autonomia e criatividade estará gravemente prejudicado.

Esta tese de Gramsci é o desdobramento pedagógico do seu imanentismo filosófico. Ou seja: a ideia do trânsito da heteronímia escolar (ensino fundamental) para a autonomia intelectual e moral (ensino médio) é a aplicação pedagógica do que ele afirmara (Caderno 11) sobre a passagem do reino da necessidade ao da liberdade, referindo-se a Marx: "Eis porque a proposição [de Marx] da passagem do reino da necessidade ao da liberdade deve ser analisada e elaborada com muita atenção e acuidade" (Gramsci, 1975a, p. 1489). Com efeito, para a filosofia da práxis, não existe, a não ser ideológica e metafisicamente, um momento histórico de pura liberdade ou de autonomia absoluta. Existe, concretamente, a luta cotidiana do ser humano para ampliar o espaço da liberdade e da autonomia. À luz desta visão filosófica, compreende-se a preocupação de Gramsci para com a fase escolar do ensino médio, por este representar o momento catártico mais delicado e importante na vida da pessoa, quando desabrocha o valor da autonomia que é a liberdade de se posicionar.

Dos anos de 1937 até os dias de hoje, passaram-se muitas décadas e os intelectuais marxistas continuaram buscando a concepção e as práticas pedagógicas mais condizentes com o axioma marxiano da articulação entre o trabalho produtivo e o trabalho escolar. Um nome importante da pedagogia marxista contemporânea é Mário Alighiero Manacorda.

Sobre o principio pedagógico específico do ensino médio, retoma ele o tema da indefinição natural e heurística dos adolescentes que estão em busca de autonomia, identidade pessoal e inserção social. Ajudá-los a descobrir, aos poucos, por meio de repetidos ensaios, sua identidade profunda é tarefa da formação escolar média, oferecendo uma formação omnilateral. Mas, cuidado: formação omnilateral ou integral não significa saber fazer um pouco de tudo ou conhecer os fundamentos científicos de todos os ramos da tecnologia, mas sim saber fazer com excelência algo em sintonia com o próprio talento e, ao mesmo tempo, saber e poder usufruir de todos os bens produzidos pela civilização contemporânea. Está assim lançada uma proposta original da formação omnilateral: aprender a produzir e a desfrutar:

Diante das experiências do mundo moderno, nós precisamos mirar o mais possível na preparação do aluno não somente para si mesmo, mas também para entrar na sociedade, se não com a capacidade de ser um produtor de cultura em todos os campos, pelo menos com a capacidade de desfrutar, isto é, de saber gozar de todas as contribuições da civilização humana, das artes, das técnicas, da literatura. (Manacorda, 2007b, p. 21) 
O autor disserta sobre currículo e escola de tempo integral para o ensino médio à luz da teoria gramsciana da integração do reino da necessidade com o reino da liberdade. O currículo proposto é estruturado por um núcleo de ensinamentos rigorosos, necessários para o jovem se tornar um homem moderno, e por um conjunto de atividades livremente escolhidas. A escola deve ser o espaço dos adolescentes, onde possam vivenciar unitariamente momentos de formação obrigatória e outros de formação livre:

\begin{abstract}
Para isto se precisa de uma escola que ministre o mais possível ensinamento rigorosos - difíceis a serem determinados - do que é necessário ao homem para ser moderno; mas que possibilite ao mesmo tempo um espaço em que cada um se forme livremente naquilo que é de seu gosto: arte, música, matemática, aeromodelismo, radiotelegrafia, astronomia, esporte, ou até mesmo técnicas artesanais. É preciso que a escola, ao invés de ser um lugar aberto cinco horas diárias, durante nove meses por ano e pelo resto do tempo permanecer fechada e vazia, seja o espaço dos adolescentes, onde estes recebam da sociedade adulta tudo o que é possível receber e ao mesmo tempo sejam estimulados em suas qualidades pessoais e capacitados de gozar todos os prazeres humanos. (Idem, ibid.)
\end{abstract}

A maioria das reformas curriculares pretende integrar os saberes obrigatórios com os optativos, ampliando o turno do horário escolar obrigatório. Entretanto, a ideia mais importante da fórmula pedagógica marxiana, assim como compreendida e desenvolvida por Gramsci e Manacorda, é integrar o reino da necessidade com o da liberdade, reduzindo progressivamente o espaço da obrigatoriedade escolar (turno) em função da formação em liberdade (contra turno).

Para nós, a grande questão é a seguinte: como priorizar na escola média brasileira a dimensão da formação para a autonomia, quando a liberdade para a maioria é tão exígua? Como proteger o direito dos adolescentes a um tempo justo de "indefinição profissional ativa e heurística", quando, de um lado, a minoria de jovens da classe dirigente usufrui de inúmeros anos de formação e "indecisão" profissional, enquanto, de outro lado, a imensa maioria, para sobreviver, é forçada a uma definição profissional precoce? A resposta a essa problemática passa pela luta política que visa a tornar a sociedade mais justa e igualitária e, ao mesmo tempo, pela defesa de concepções e práticas pedagógicas que fortaleçam o ensino médio unitário não profissionalizante e para todos.

Lamentavelmente, o próprio termo "médio" obscurece, pela semântica, o entendimento correto da natureza desta fase escolar. "Médio" significa um momento equidistante do ensino fundamental e do superior. Trata-se de uma palavra, portanto, em si mesma vazia de sentido, definida pelos extremos. Na verdade, esta etapa do ensino é a fase da plenitude e da maturidade da pessoa, quando o jovem aprende a produzir e dirigir a si mesmo, como pressuposto básico para produzir e dirigir a sociedade. 
Um texto oficial do Ministério da Educação, "Ensino Médio Inovador", confessa que: "prevalece a lacuna de programas consistentes no âmbito curricular para o Ensino Médio não profissionalizante, 8.366 .100 matrículas (senso 2008), que correspondem a mais de 90\% das matrículas do ensino médio regular" (Brasil, 2009, p. 13). Qualificar esse dado como "lacuna" é eufemismo. Na verdade, é um dado estatístico que revela que o ensino médio regular não profissional e público é um desastre escolar nacional. Não é um problema que possa ser resolvido com "uma nova organização curricular". Além da grave contradição social estrutural, reflete a carência de políticas públicas adequadas.

Entretanto, diante da proposta de se priorizar uma profunda reforma do ensino médio não profissionalizante, com maciços investimentos, não raramente levanta-se a objeção:

O que fazer com os milhares de jovens que estão entrando no mercado de trabalho todo ano? Não seria o ensino técnico uma forma de ampliar a formação dos jovens que já estão entrando no mercado de trabalho? Seria injusto negar a estes jovens um processo de qualificação que valorize a sua inserção no "mercado" de trabalho. Ou seja, o ensino técnico é uma necessidade atual decorrente da dualidade estrutural. Sendo uma necessidade, devemos também nos ocupar de qualificá-los. (Ronaldo Lima Araújo, por e-mail, em 14 set. 2009)

A objeção é precisa. Todavia, a necessidade assistencialista decorrente da dualidade estrutural da sociedade não justifica o abandono, por parte do Estado, do ensino médio público não profissionalizante, cujo triste e ininterrupto declínio de sua qualidade começou nos governos populistas e continua até hoje mascarado pela crítica ao elitismo do antigo ensino secundário público, que precisava ser modernizado e democratizado, não destruído. Seu objetivo de formar dirigentes para uma sociedade urbana pós-agrária permanece válido e suas portas precisam estar objetivamente abertas a todos os cidadãos.

Obviamente, uma política centrada na recuperação da qualidade do ensino médio não profissionalizante não significa abandonar os milhares de jovens forçados a entrar precocemente no mercado de trabalho a cada ano. É sempre oportuno lembrar que a iniciativa privada é muito sensível à demanda do mercado. Todavia, a competência própria e prioritária do governo é oferecer um ensino médio não profissionalizante, de qualidade, para todos. Afinal, se a Sociedade Política não cuidar deste ensino, a Sociedade Civil jamais o fará.

\section{Conclusão: em outra linguagem}

Tenho uma filha de 17 anos, Paola. Irritava-me sua indefinição profissional. De vez em quando, mudava de ideia: do curso de Química para o de Biologia, deste para 
o de Sociologia ou de Filosofia. Um dia, percebi o óbvio. Embora aparentasse se acomodar na indefinição, não era isso que ela desejava. Ao contrário, buscava a definição com bastante ansiedade, pois o seu entorno social a pressionava para uma precoce definição profissional, ao invés de discutir com ela temas de cultura geral relevantes. Ou seja, a indefinição da Paola não era um estado de inércia ou de mórbida espera passiva. Era um buscar racional, profunda, interior. Consultava bibliotecas, levava algum livro para o quarto. Visitava universidades. Relacionava-se e conversava sobre o assunto com professores, com amigos. Pedia algum dinheiro para assistir a palestras, visitar exposições, museus e também para prestar seleção como "treineira" nos vestibulares. Convivendo com Paola comecei a defender o direito à indefinição profissional, ativa e heurística, pelo menos até os 18/20 anos, para todos os jovens adolescentes.

Para todos? Como defender o mesmo direito para Michael Leão, chamado de Maicom, filho da minha empregada doméstica? Maicom tem 13 anos e cursa a $7^{0}$ série. Sua mãe é arrimo de família. Diz não ter pai. Quaisquer cinco reais que leve para casa faz diferença no orçamento familiar. Diz que deseja ser como eu, trabalhar em universidade, escrever, viajar. Ou, então, quer ser mecânico ou tapeceiro. A necessidade matará seu direito à indefinição profissional. Um processo de indefinição profissional de 4/5 anos é natural; custa, mas é indispensável, sobretudo quando se visa a formar um dirigente da sociedade, isto é, um cidadão pleno. É um processo que exige capital cultural, social e econômico. Maicom precisa conviver com livros, computador, viajar, se relacionar de forma rica e variada, ler e escrever, sem que falte nada de essencial em sua casa.

Maicom será encaminhado para uma prática produtiva imediata e/ou para um curso profissionalizante rápido que o ajude a desempenhar algum serviço remunerado. Qual a tendência profunda ou o talento de Maicom? Vários. Mas não haverá tempo e condições materiais para ele identificá-los e cultivá-los. Na melhor das hipóteses, será uma matrícula entre as mais de $90 \%$ do ensino médio regular público, noturno, para ter diploma.

Quem poderá abrir-lhe o horizonte da possibilidade concreta e pessoal de ser um dia um futuro dirigente? Como lhe mostrar que, no futuro, deverá sim exercer alguma atividade prática produtiva, mas também se tornar um cidadão pleno, isto é, um dirigente? Como fazer com que acredite sinceramente nisto? Quem o educará nesse sentido, formando-o na profissão para a qual demonstra mais talento e na responsabilidade política? A resposta é que compete ao Estado educar nessa perspectiva todos os milhões de Maicom da nação, por meio de um estudo de elevada qualidade, de amplo espectro cultural, não assistencialista.

Para conseguir esse objetivo, o Estado precisa priorizar em suas políticas de reformas o ensino médio não profissionalizante, possibilitando à família de Maicom sobreviver sem a contribuição imediata deste adolescente, oferecendo-lhe um ensino 
médio rico de recursos didáticos, onde se leiam, entre outros, os Épicos de Homero, o Discurso de Cícero contra Catilina, o Dialogo sobre os dois maiores sistemas de Galileu, Memórias do cárcere, de Graciliano Ramos; onde se estudem e discutam os velhos e novos instrumentos tecnológicos; onde se organizem viagens de estudo para vários lugares do Brasil e também (por que não?) para o exterior; onde os alunos sejam orientados e acompanhados, pela própria instituição escolar, individualmente, nas atividades de seu gosto, dentro ou fora da escola, durante o período oposto ao horário da escolarização obrigatória. Somente quando Maicom conseguir se projetar interiormente como um futuro dirigente desta sociedade, tomarão sentido para ele os debates de cultura geral anteriormente exemplificados. Caso contrário, seu interesse encolherá mesquinhamente em aspectos prático-profissionais.

\section{Referências}

BRASIL. Ministério da Educação. Secretaria de Educação Básica. Ensino médio inovador. Brasília, DF, abr. 2009.

CHAGAS, V. Entrevista. In: Buffa, E.; Nosella, P. Memória e educação: da história de vida de educadores à história da educação brasileira. Brasília, DF: INEP/CNPq, 1988. (Relatório final de pesquisa não publicado).

DAGMAR, M.L.Z. Breves anotações sobre a história do ensino médio no Brasil e a reforma dos anos 1990. In: ENSINO MÉDIO E ENSINO TÉCNICO NO BRASIL E EM PORTUGAL: raízes históricas e panorama; Programa de Estudos Pós-Graduados em Educação: Psicologia da Educação, Puc/sp (Org.). Campinas: Autores Associados, 2005.

GRAMSCI, A. Lettere dal cárcere. Curadores: Sergio Caprioglio e Elsa Fubini. Torino: Einaudi, 1975a.

GRAMSCI, A. Quaderni del cárcere. Torino: Einaudi, 1975b. v. 1-v. 4.

GRAMSCI, A. Os intelectuais; O princípio educativo; Jornalismo. In: Gramsci, A. Cadernos do cárcere. Ed. e trad. Carlos Nelson Coutinho. Rio de Janeiro: Civilização Brasileira, 2000. v. 2.

LEMME, P. Entrevista. In: Buffa, E.; Nosella, P. Memória e educação: da história de vida de educadores à história da educação brasileira. Brasília, DF: INEP/CNPq, 1988. (Relatório final de pesquisa não publicado).

MANACORDA, M.A. Marx e a pedagogia moderna. Campinas: Alínea, 2007a.

MANACORDA, M.A. Aos educadores brasileiros. Campinas, 2007b. (DvD). 
Ensino médio: em busca do princípio pedagógico

MAURO, R. Il lavoro produttivo em Makarenko. Scuola e Cittá, Roma, n. 5, 31 maio 1980.

Recebido em 4 de junho de 2011.

Aprovado em 10 de setembro de 2011. 